\title{
Ventricular fibrillation threshold for AC shocks of long duration, in dogs with normal acid-base state
}

\author{
JANET R. SCOTT, W. R. LEE, and S. ZOLEDZIOWSKI \\ Department of Occupational Health, University of Manchester, and Department of \\ Electrical Engineering, University of Salford
}

\begin{abstract}
Scott, Janet R., Lee, W. R., and Zoledziowski, S. (1973). British Journal of Industrial Medicine, 30, 155-161. Ventricular fibrillation threshold for AC shocks of long duration, in dogs with normal acid-base state. Earlier experimental studies of threshold ventricular fibrillating currents passing along the common accident pathway of forelimb to leg have shown a wide range of results for any one shock duration. In the present investigation the acid-base state of the experimental animals (dogs) was held within normal limits. It was found that whereas the mean minimum fibrillating current, $82 \cdot 2 \mu \mathrm{A}$ for 3-second shocks, was within the values found by other workers, the range of results was reduced considerably to 67-101 $\mu \mathrm{A}$. Further, when the shock duration was increased, in stages, up to 60 seconds, again keeping the acid-base state within normal limits, the mean minimum fibrillating current did not alter markedly (being $80 \mu \mathrm{A}$ at 60 seconds) but the range of results progressively fell and was $73-88 \mu \mathrm{A}$ at 60 seconds. In the light of these findings the mechanism of ventricular fibrillation is discussed.
\end{abstract}

Ventricular fibrillation is one of the more serious consequences of electric shock. As in other situations where preventive measures are to be applied it is important to know about the magnitude of the hazard likely to be associated with the risk. In their recent review, Dalziel and Lee (1968) published data derived from a number of sources from which it was clear that for any given shock duration there was a very wide variation of threshold fibrillating currents when these currents passed along the common accident pathway of forelimb to leg.

Ventricular fibrillation has been studied from various aspects since it was first described by Prevost and Battelli, in 1899. Ferris, King, Spence, and Williams (1936), Kouwenhoven et al. (1959), and Kiselev (1963) have established minimum thresholds of fibrillation in a variety of species and under a variety of conditions. An electric current was used to induce fibrillation and the effect of many param- eters on the minimum fibrillation current (MinFC) was investigated. Current frequency, duration, and pathway were examined as well as animal weight and the effect of shock timing in relation to the heart cycle. In each case the MinFC results for a given shock duration and pathway exhibited a wide variation. In none of the experiments was the acidbase or plasma ionic state of the animal measured or controlled.

Since the publication of that work acid-base state has been shown to affect plasma cation levels. Elevated potassium ion $\left(\mathrm{K}^{+}\right)$levels have been regularly associated with acidosis whether of respiratory origin (Scribner and Burnell, 1955; Young, Sealy, and Harris, 1954; Brown and Goott, 1963) or metabolic origin (Keating et al., 1953; Brown and Goott, 1963). Conversely, respiratory alkalosis (Scribner and Burnell, 1955; Brown and Goott, 1963) and metabolic alkalosis (Keating et al., 
1953; Brown and Goott, 1963) have both been shown to cause a slight fall in plasma $\mathrm{K}^{+}$ion concentrations. Experiments on isolated hearts indicate that potassium ion concentration of the perfusate or the potassium/calcium ratio (Antoni, 1961) plays an important part in determining the vulnerability of the heart to fibrillation.

Experiments have also been undertaken to show the effect of acid-base state on fibrillation thresholds induced by direct current pulses applied directly to the heart. These have produced conflicting results (Gerst, Fleming, and Malm, 1966; Dong, Stinson, and Shumway, 1967; Turnbull and Dobell, 1966) (see Table 1). Metabolic acidosis, however, as a rule lowers the fibrillation threshold and, according to Turnbull and Dobell, respiratory acidosis has the same effect. This effect on cardiac vulnerability may have been mediated by acidosis alone or by induced variations in plasma potassium or the potassium/ calcium ratio which are associated with acidosis.

The possibility that the animals used by Ferris, by Kouwenhoven, and by Kiselev may have drifted into an abnormal acid-base state is supported by the work of Severinghaus (1959), who demonstrated that anaesthesia will induce acidosis in humans. He explained this as the result of a decrease in sensitivity to arterial carbon dioxide pressure $\left(\mathrm{PaCO}_{2}\right)$ in the respiratory centre. A reduced response to changes in $\mathrm{pH}$ has also been shown to occur as a result of barbiturates by Robson, Houseley, and SolisQuiroga (1963), although fibrillation thresholds are not affected by barbiturate anaesthesia (McIntosh, Starmer, and Whalen, 1966). It is possible, therefore, that the experimental animals of Ferris, of Kouwenhoven, and of Kiselev might have been in various degrees of acidosis when their fibrillation thresholds were established. The application of repeated electric shock and periods of fibrillation may have further aggravated the acidotic state.

The wide variation in MinFC results found by these workers could, therefore, be attributed to fluctuations in acid-base state and associated changes in plasma potassium ion concentration during the course of the experiments. The first aim of the present series of experiments was to test this hypothesis.

Previous investigations have clearly demonstrated the influence of shock durations between 8.3 milliseconds and 5 seconds on MinFCs. There is, however, little information on shocks of over 5 seconds duration. Kiselev (1963) found that the MinFC established with shocks of 10, 20, and 30 seconds did not differ 'in essence' from that at 3 seconds. For long shock durations, however, asphyxial changes might increasingly exert their effect and lower the threshold value (Gerst $e t$ al., 1966). The second aim was then to investigate the effect of long shock durations on the MinFC.

\section{Method}

Sixteen dogs (11 beagles and 5 mongrels) weighing between 10.4 and $18.6 \mathrm{~kg}$ were used in these experiments. The animals were anaesthetized by an intravenous injection of $300 \mathrm{mg}$ of $2.5 \%$ thiopentone sodium. This allowed insertion of a cuffed endotracheal tube, the free end of which was connected to a respiratory pump which delivered a $3: 1$ mixture of nitrous oxide $\left(\mathrm{N}_{2} \mathrm{O}\right)$ and oxygen. The $\mathrm{N}_{2} \mathrm{O}$ anaesthetic was supplemented when necessary by further doses of thiopentone sodium, the average dose rate being $10.63 \mathrm{mg} / \mathrm{kg} / \mathrm{hr}$.

The left femoral artery and vein were cannulated, the former to monitor arterial blood pressure via a pressure transducer (Statham, P23 Series) and for withdrawal of blood samples, and the latter to allow infusion of sodium bicarbonate and anaesthetic. The right jugular vein was also cannulated, the catheter being introduced into the right ventricle. The free end of the catheter was attached to a pressure transducer (Statham, P23 Series) to monitor ventricular activity when it was not possible to use the electrocardiogram (ECG). The signals obtained from the two transducers were amplified (Honeywell Amplifiers, type 2585) and displayed on meters (Wessex, type M31) and on an oscilloscope (Telequipment, type D43R). The amplified signal was also recorded on an ultraviolet recorder (Honeywell, type 2500). ECG leads were attached to all four limbs of the dog and the amplified signal (Honeywell amplifier, type 2581), usually limb lead II, was displayed on the oscilloscope and recorded.

Arterial samples were withdrawn at regular intervals throughout the experiment to ascertain the acid-base

TABLE 1

Effect of Acid-base State on Ventricular Fibrillation Thresholds

\begin{tabular}{c|c|c|c|c}
\hline \multicolumn{1}{c|}{ Author } & Respiratory acidosis & Respiratory alkalosis & Metabolic acidosis & Metabolic alkalosis \\
\hline $\begin{array}{l}\text { Dong } \text { et al. (1967).. } \\
\text { Gerst et al. (1966).. }\end{array}$ & $\rightarrow$ & $\uparrow$ & - & - \\
Turnbull et al. (1966) & $\vec{\downarrow}$ & $\rightarrow$ & $\downarrow$ & $\uparrow$ \\
\hline
\end{tabular}

Where: $\rightarrow=$ no change in MinFC from control value

$\uparrow=$ increase in MinFC from control value

$\downarrow=$ decrease in MinFC from control value 
state of the animal. The $\mathrm{PaCO}_{2}, \mathrm{PaO}_{2}$, and $\mathrm{pH}$ values were read from Radiometer electrodes (types E5036, E5044, and E5021 respectively). As the oxygen electrode was calibrated with oxygen-free water and water equilibrated with room air, the $\mathrm{PaO}_{2}$ readings were corrected for water/blood difference by multiplying by 0.97 . This figure was obtained by tonometry with water and blood equilibrated with different oxygen mixtures (Adams and Morgan-Hughes, 1967). The haemoglobin level was determined on an EEL colorimeter using the cyanmethaemoglobin method. The base deficit (BD) was determined from these measurements by use of the alignment nomogram of Siggaard-Andersen (1963). These measurements provided the data necessary for acid-base control.

The acid-base state was maintained throughout the experiment within preset normal limits, namely:

pH

$\mathrm{PaCO}_{2}$

$7 \cdot 33$ to $7 \cdot 42$

$\mathrm{PaO}_{2}$

Arterial BD

Arterial $\mathbf{K}^{+}$

Arterial BP

Rectal temp.

38 to $45 \mathrm{mmHg}$

over $80 \mathrm{mmHg}$

-5 to base excess $+3 \mathrm{mEq} / \mathrm{l}$

1.5 to $5.0 \mathrm{mEq} / \mathrm{l}$

over $100 \mathrm{mmHg}$

96 to $102^{\circ} \mathrm{F}$

The $\mathrm{PaCO}_{2}$ was controlled by varying the tidal volume and rate of the respiration pump and the $\mathrm{PaO}_{2}$ by varying the ratio of $\mathrm{O}_{2}: \mathrm{N}_{2} \mathrm{O}$. The arterial $\mathrm{BD}$ was controlled by infusion of molar sodium bicarbonate.

Plasma sodium and potassium ion levels were monitored by using an EEL flame photometer (Mark II). Rectal temperature was measured throughout the experiment, and the animal's temperature was maintained as necessary with table heaters.
Experimental production of fibrillation

Ventricular fibrillation was induced by passing $50 \mathrm{~Hz}$ currents of $3,10,30$ or 60 seconds duration from the left forelimb to the right hindlimb (Figure). The same leads were used to complete the shock circuit and the ECG circuit. The equipment used for the application of shocks allowed the shock duration to be preset and also incorporated the facility for short circuiting and earthing the ECG amplifier inputs during the shock period. The shock current I passing through the animal was preset by adjusting the voltage $\mathrm{V}$ and by varying the external resistance $R_{1}$ in the shock circuit according to Ohm's Law $I=V /\left(R_{1}+R_{2}\right)$, where $R_{2}$ is the animal resistance.

The shock current was measured with an ammeter (Avometer, Model 8, Mark III), and the trace of current magnitude and duration was included permanently on the UV record. Three shocks were applied at each current value and if fibrillation did not occur the current was increased in steps of approximately $20 \mathrm{~mA}$ until at least one of the three shocks resulted in fibrillation. The current was then further increased in the same way until all three shocks caused fibrillation. The lowest current at which one or more of the shocks resulted in fibrillation was termed the minimum fibrillating current (MinFC) and the lowest current at which all three shocks caused fibrillation, the minimum $100 \%$ fibrillating current (Min100\%FC).

When fibrillation occurred a direct current countershock of 60 to 70 joules was applied across the chest to defibrillate the heart. The sides of the chest had previously been shaved and electrode jelly applied to the skin to improve the contact between the skin and the defibrillator electrodes.

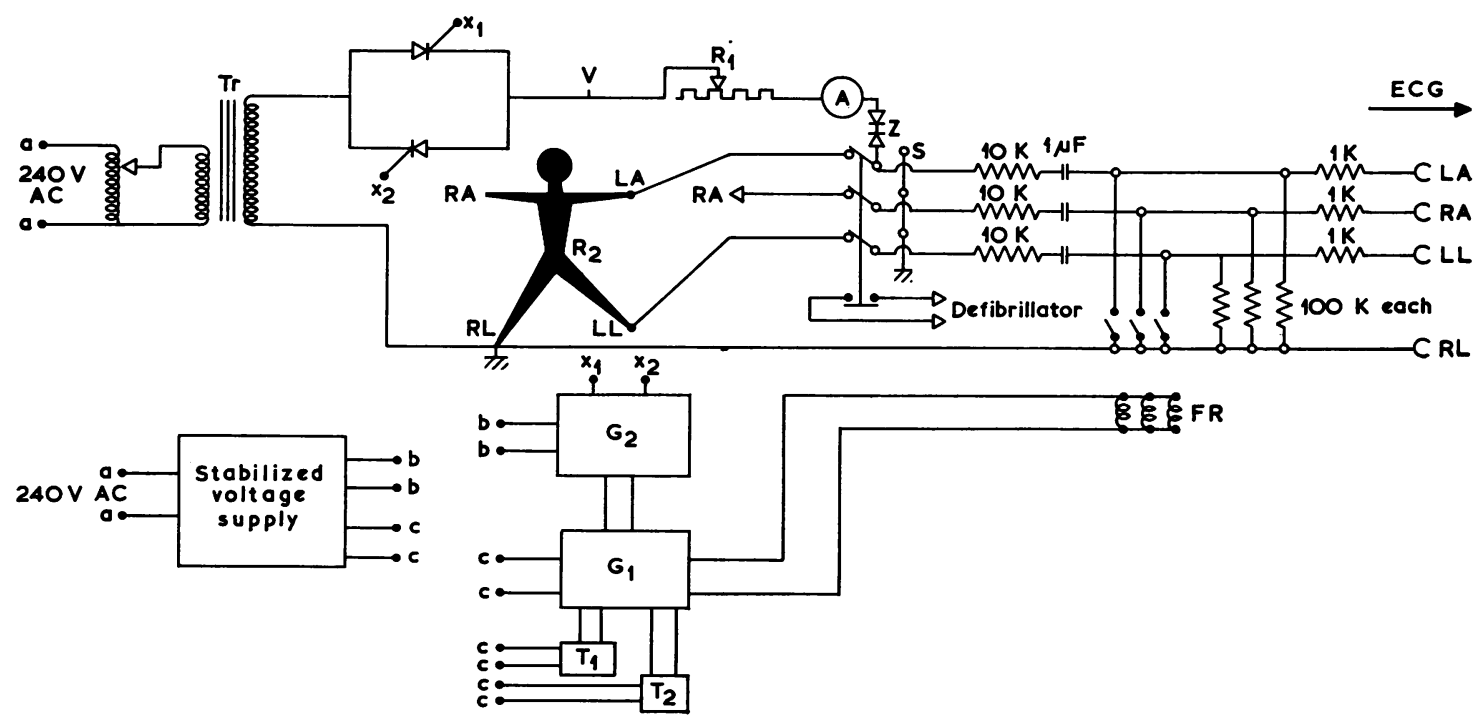

FIGURE The shock-producing equipment and current pathway-simplified circuit diagram. V=point for voltage measurement $; R_{1}=$ external resistance (range 0 to $10 \mathrm{~K} \Omega$ ); $R_{2}=$ animal resistance (LA to $\mathrm{RL}$ ); $\mathrm{A}=$ ammeter; $\mathrm{S}=\mathrm{\text {switch}}$; $F R=$ fast acting relays; $G_{1}=$ generator $I ; G_{2}=$ generator II; $T_{1}=$ timer $I ; T_{2}=$ timer II; $T r=$ transformer (output voltage 0 to $500 \mathrm{~V}) ; X_{1}$ and $X_{2}=$ gates of silicone-controlled rectifiers. 


\section{Results}

All the results were obtained while the acid-base state of the animals was within 'normal' limits, as defined above. The results are considered in two sections.

Effect of a normal acid-base state on MinFCs using 3-second shocks

The MinFC values established in the present experiments are shown in Table 2 . The mean MinFC value is $82.2 \mathrm{~mA}$ with a range of 67 to $101 \mathrm{~mA}$. Table 3 shows the wide range of MinFC results of Kouwenhoven, Ferris, and Kiselev compared with that of the present series. A comparison of the spread of MinFC around the mean is demonstrated for each author's results by the ranges, the standard deviations (SD), and the co-efficients of variation. These values suggest a real decrease in the range of the present results despite discrepancies in the numbers of animals used by different authors.

There was no significant correlation between animal weight and MinFC in the present results $(P=>0.1 ; r=0.4235 ; n=9)$ although such $a$ correlation has been demonstrated in the results of Kiselev.

Effect of long shock duration on MinFC

The mean MinFC value which had been established using 3-second shocks was found to change little on
TABLE 2

\begin{tabular}{c|c} 
MinFC VALUES & $\begin{array}{c}\text { FOR } \\
\text { DURATION }\end{array}$ \\
\multicolumn{2}{c}{ OF 3 SECONDS } \\
\hline Dog number & $\operatorname{MinFC}(\mathrm{mA})$ \\
\hline IV & 67 \\
VI & 80 \\
VII & 81 \\
VIII & 90 \\
IX & 77 \\
X & 71 \\
XI & 99 \\
XII & 101 \\
XIII & 34 \\
Mean & $82 \cdot 2 \pm 11 \cdot 31$ (SD) \\
\hline
\end{tabular}

increasing the shock duration (Table 4). The maximum variation of means is $9.2 \mathrm{~mA}$, an order of difference which is to be expected in this type of biological assay.

Although the mean MinFC appears to be unaffected by shock duration, the range of MinFC can be seen to decrease as shock duration increases. Thus the range falls from $34 \mathrm{~mA}$ for 3 -second shocks to $15 \mathrm{~mA}$ for shocks of 60 seconds duration.

It should be noted that the standard deviations quoted in Tables 2, 3, and 4 which were obtained by the usual statistical methods from the values of

TABLE 3

Minimum Fibrillation Current Results-Dogs

\begin{tabular}{|c|c|c|c|c|c|c|c|c|}
\hline & & \multirow[t]{2}{*}{ No. of dogs } & \multirow{2}{*}{$\begin{array}{c}\text { Average } \\
\text { weight } \pm \\
\text { (range) }(k g)\end{array}$} & \multirow{2}{*}{$\begin{array}{l}\text { Total no. } \\
\text { of shocks }\end{array}$} & \multirow{2}{*}{$\begin{array}{c}\text { Shock } \\
\text { duration } \\
(\text { sec) }\end{array}$} & \multicolumn{3}{|c|}{$\operatorname{MinFC}(m A)$} \\
\hline & & & & & & $\begin{array}{c}\text { Mean } \\
( \pm S D)\end{array}$ & Range & $\begin{array}{c}\text { Co-efficient } \\
\text { of variation } \\
(\%)\end{array}$ \\
\hline $\begin{array}{l}\text { Kouwenhoven et } \\
\text { (1959) } \\
\text { ditto } \\
\text { Ferris et al. (1936) } \\
\text { Kiselev (1963) } \\
\text { Present study .. }\end{array}$ & $\begin{array}{l}a l . \\
\cdots \\
\\
\cdots \\
\cdots \\
\cdots\end{array}$ & $\begin{array}{r}10 \\
4 \\
10 \\
35 \\
9\end{array}$ & $\begin{array}{l}\quad- \\
22 \cdot 5(18-26) \\
11 \cdot 5(6-25) \\
15 \cdot 1(10 \cdot 4- \\
18 \cdot 6)\end{array}$ & $\begin{array}{r}41 \\
18 \\
? 10 \\
? 35 \\
229\end{array}$ & $\begin{array}{l}2 \\
5 \\
3 \\
3 \\
3\end{array}$ & $\begin{array}{r}186 \cdot 5 \pm 91 \cdot 11 \\
83 \cdot 3 \pm 31 \cdot 32 \\
110 \pm 23 \cdot 07 \\
74 \pm 22 \cdot 87 \\
82 \cdot 2 \pm 11 \cdot 31\end{array}$ & $\begin{array}{l}77-400 \\
42-125 \\
70-220 \\
37 \cdot 5-136 \\
67-101\end{array}$ & $\begin{array}{l}48 \cdot 8 \\
37 \cdot 5 \\
31 \cdot 0 \\
30 \cdot 8 \\
13 \cdot 8\end{array}$ \\
\hline
\end{tabular}

TABLE 4

Effect of Shock Duration on MinfC and Related Measurements

\begin{tabular}{c|c|c|c|c|c}
\hline $\begin{array}{c}\text { Shock duration } \\
(\text { sec })\end{array}$ & No. of dogs & $\begin{array}{c}\text { Total no. of } \\
\text { shocks }\end{array}$ & $\begin{array}{c}\text { Mean MinFC } \\
\pm S D(m A)\end{array}$ & $\begin{array}{c}\text { MinFC range } \\
(m A)\end{array}$ & $\begin{array}{c}\text { MinFC to } \\
\text { Minlo0\% } \\
\text { difference }(m A)\end{array}$ \\
\hline 3 & 9 & 229 & $82 \cdot 2 \pm 11$ & $67-101$ & $67-157$ \\
10 & 5 & 63 & $78 \pm 11$ & $61-90$ & $61-135$ \\
30 & 7 & 57 & $73 \pm 9$ & $62-82$ & $62-94$ \\
60 & 4 & 29 & $80 \pm 7$ & $73-88$ & $73-99$ \\
\hline
\end{tabular}


MinFC are, in the present experiments, of approximately the same magnitude as the error due to the method. In the results from the other workers the standard deviations are greater and are at least twice the size of the error due to the method.

The difference between MinFC and Min $100 \%$ FC also decreases as the shock duration increases, the Min $100 \% \mathrm{FC}$ value closing towards the more stable MinFC value (Table 4).

\section{Discussion}

Slight differences of method should be taken into account when the MinFC results of different authors are compared. Kouwenhoven, for example, established more than one MinFC value on each dog for each shock duration. He also used shock durations of 2 and 5 seconds as opposed to the 3 seconds of Ferris and Kiselev.

The major difference in method between the present experiments and those of earlier workers, however, is acid-base control. Table 3 demonstrates the reduction in range in the present MinFC results where the acid-base state was controlled. This suggests that varying degrees of acidosis have contributed to the wide variation of MinFC in previous investigations.

As yet no single mechanism has been proposed that can fully explain ventricular fibrillation. This makes it difficult to postulate the possible effect of various factors on the phenomenon. There are, however, certain conditions which must be fulfilled in order to initiate and maintain fibrillation. These conditions include (a) a stimulus to initiate the disorder, $(b)$ changes in conduction velocity and duration of refractory period in part or the whole of the myocardium, and $(c)$ sufficient tissue mass to maintain the fractionated activity. One can therefore attempt to link changes in acid-base state with one or more of these factors in order to explain the results shown in Table 3.

\section{Effect of acid-base state on MinFC range}

The dog's heart has frequently been demonstrated to be of sufficient mass to maintain fibrillation (West and Landa, 1962). Thus condition (c) above is satisfied. Abnormalities of acid-base state are seen as exerting an effect on MinFCs by way of their influence on plasma potassium ion concentration. This in turn will affect conditions $(a)$ and $(b)$.

The stimulus used to induce fibrillation in the experiments under consideration is electric shock. This acts by inducing heteroectopic foci in the myocardium by causing cardiac fibres to function as pacemakers. This pacemaker effect would be enhanced by a decrease in potassium conductance which has been shown to occur with a decrease in extracellular potassium (Antoni, 1961). Such a decrease occurs in alkalosis (Scribner and Burnell, 1955; Brown and Goott, 1963). An increase in extracellular potassium, as occurs during acidosis (Scribner and Burnell, 1955), would again reduce potassium conductance.

The presence of sufficient tissue mass $(c)$ and the availability of excitable stimuli $(a)$ would not induce or sustain fibrillation, however, if the myocardium was in an absolutely homogenous state. Re-entry can occur only if different areas of the heart differ in conduction velocity and/or duration of refractory period $(b)$.

A decrease in conduction velocity and consequent increase in vulnerability may result from depolarization initiated from a membrane potential which is lower (i.e., less negative) than the normal resting potential (RP). This may occur when (1) depolarization begins during phase 3 of the cardiac action potential (AP) before repolarization is completed, e.g., as in stimulation by electric current, or (2) when the extracellular potassium is elevated (Weidmann, 1956) and the membrane potential is again less negative than the RP. The latter situation would occur during acidosis.

Duration of the refractory period is another important factor in perpetuation of fibrillation, and is again affected by abnormal potassium ion distribution. It has been demonstrated by Han, Garcia de Jalon, and Moe $(1964,1966)$ that dispersion of the refractory state over the myocardium facilitates fibrillation. The probable explanation is the increased opportunity of re-entry of an impulse from a region with a long refractory period into a region with a shorter refractory period. Hoffman and Cranefield (1960) have emphasized the difference between the duration of action potential in Purkinje and ventricular fibres as a factor contributing to re-entry. Low extracellular potassium has been shown by Gettes and Surawicz (1968) to increase the difference between duration of action potential in these two types of fibres. Both high and low extracellular potassium ion concentrations have, then, been shown to facilitate ventricular arrhythmias. Moreover, it is possible that the potassium/calcium ratio may be involved. For example, the spontaneous fibrillation that often follows hypercapnia has been attributed to a simultaneous increase in plasma potassium and decrease in plasma calcium concentration (Goott and Miller, 1959).

Thus it seems possible that the abnormal plasma potassium ion levels associated with an uncontrolled acid-base state may have caused, in part at least, the wide range of MinFC in the work of Ferris, Kouwenhoven, and Kiselev.

Effect of shock duration on the MinFC and associated values

There are two variables of importance when the 
range of MinFC and the difference between MinFC and Min $100 \% \mathrm{FC}$ with different shock durations are compared (Table 4). They are shock duration and current value. Increased shock duration or current can both increase the probability of fibrillation but as a result of different mechanisms.

An increase in shock duration for a given shock current (over threshold value) is considered to exert its effect by allowing the pacemaker-like activity of the foci to become more firmly established. The number of foci initiated would not vary but the likelihood of their extinction on cessation of the current would be reduced, hence the increased probability of fibrillation being initiated and perpetuated. It is also possible that the change in position and shape of the heart which might occur during long shocks could cause new foci to be established, again facilitating fibrillation.

An increase in shock current exerts a similar effect but by a different mechanism. For a given shock duration, an increase in current is considered to increase the number of points in the myocardium responding to current flow and the initiation of more potential ectopic pacemakers. Those areas most vulnerable to stimulation will be affected earlier in their relative refractory period than less vulnerable areas. The foci will, then, be firing asynchronously and will cause irregular spread of excitation and non-uniform recovery. This temporary dispersion of refractoriness, as mentioned above, facilitates fibrillation.

Although these two concepts are described separately they are not, in practice, mutually exclusive. The decrease in MinFC range with increase in shock duration is seen as a result of extending the period available for the current to exert its effect. The decrease in MinFC to Min $100 \% \mathrm{FC}$ range is the combined effect of the mechanisms associated with shock current and duration. A state of hypercapnia and/or elevated potassium ion levels, which might occur with prolonged shocks, would further facilitate the perpetuation of fibrillation.

The lack of effect of shock duration on the Mean MinFC value is a special case. There appears to be a threshold limit value of current required to initiate fibrillation regardless of duration. Currents below this seem unable to affect the cardiac fibres early enough in their relative refractory period to induce a sufficient increase in action potential frequency to degenerate into fibrillation. Shock duration would have no effect in this case although the basal value will vary according to the current pathway involved.

\section{Conclusions}

Control of the acid-base state and associated stability of the plasma potassium ion concentrations has produced a narrow range of MinFC values. These results seem to confirm the hypothesis that one of the factors responsible for the variability of MinFC results of earlier workers was an uncontrolled and increasing metabolic and possibly respiratory acidosis.

Shocks of $3,10,30$, and 60 seconds duration produced very similar mean MinFC values. The stability of mean MinFC over this wide range of shock duration suggests a basal threshold of fibrillation. Currents below this threshold seem unable to induce fibrillation regardless of shock duration. The range of MinFC and MinFC to Min $100 \% \mathrm{FC}$, both, however, decrease with increasing shock duration.

This work and further work at present in progress on shocks of shorter duration will enable the prediction of thresholds of ventricular fibrillating current, under accident conditions, to be made with greater accuracy than hitherto.

We are grateful to the Medical Research Council for the provision of apparatus and to the Electricity Council for the grant for technical assistance.

\section{References}

Adams, A. P., and Morgan-Hughes, J. O. (1967). Determination of the blood-gas factor of the oxygen electrode using a new tonometer. British Journal of Anaesthesia, 39, 107113.

Antoni, H. (1961). Elektrophysiologische Studien zum Problem der Flimmer-Entstehung und Flimmer-Beseitigung. Beitrage zur ersten Hilfe und Behandlung von Unfallen durch elektrischen Strom, 2, 3-18.

Brown, E. B., and Goott, B. (1963). Intracellular hydrogen ion changes and potassium movement. American Journal of Physiology, 204, 765-770.

Dalziel, C. F., and Lee, W. R. (1968). Reevaluation of lethal electric currents. Transactions of Institute of Electrical \& Electronics Engineers Industry and General Applications, 1GA, 467-476.

Dong, E., Stinson, E. B., and Shumway, N. E. (1967). The ventricular fibrillation threshold in respiratory acidosis and alkalosis. Surgery, 61, 602-607.

Ferris, L. P., King, B. G., Spence, P. W., and Williams, H. B. (1936). Effect of electric shock on the heart. Transactions of the American Institute of Electrical Engineering, 55, 498-515.

Gerst, P. H., Fleming, W. H., and Malm, J. R. (1966). Increased susceptibility of the heart to ventricular fibrillation during metabolic acidosis. Circulation Research, 19, 63-70.

Gettes, L., and Surawicz, B. (1968). Effects of low and high concentrations of potassium on the simultaneously recorded Purkinje and ventricular action potentials of the perfused pig moderator band. Circulation Research, 23, 717-729.

Goott, B., and Miller, F. A. (1959). Prevention of posthypercapneic ventricular fibrillation in dogs. Journal of Thoracic and Cardiovascular Surgery, 38, 630-642.

Han, J., Garcia de Jalon, P., and Moe, G. K. (1964). Adrenergic effects of ventricular vulnerability. Circulation Research, 14, 516-524.

- , - and - (1966). Fibrillation threshold of premature ventricular responses. Circulation Research, 18, 18-25.

Hoffman, B. F., and Cranefield, P. F. (1960). Electrophysiology of the Heart, p. 200. McGraw-Hill, New York. 
Keating, R. E., Weichselbaum, T. E., Alanis, M., Margraf, H. W., and Elman, R. (1953). Movement of potassium during experimental acidosis and alkalosis in the nephrectomized dog. Surgery, Gynecology and Obstetrics, 96, 323330.

Kiselev, A. P. (1963). Threshold values of safe current at mains frequency. Problems of electrical equipment, electrical supply and electrical measurements (in Russian). Sborník MIIT, 171, 47-58.

Kouwenhoven, W. B., Knickerbocker, G. G., Chesnut, R. W., Milnor, W. R., and Sass, D. J. (1959). AC shocks of varying parameters affecting the heart. American Institute of Electrical Engineers Transactions (Communication and Electronics), 78, 163-169.

McIntosh, H. D., Starmer, F., and Whalen, R. E. (1966). A comparison of the electrical ventricular fibrillation threshold with and without anesthesia. American Heart Journal, 72, 419-420.

Prevost, J. L., and Battelli, F. (1899). La mort par les décharges électriques. Journal de Physiologie et de Pathologie Générale. 1, 577, 1085-1100; 1114-1129.

Robson, J. G., Houseley, M. A., and Solis-Quiroga, O. H. (1963). The mechanism of respiratory arrest with sodium pentobarbital and sodium thiopental. Annals of the New York Academy of Sciences, 109, 494-504.
Scribner, B. H., and Burnell, J. M. (1955). The effects of respiratory alterations of $\mathrm{pH}$ on the internal equilibrium of potassium. Journal of Clinical Investigation, 34, 919.

Severinghaus, J. W. (1959). Respiration and hypothermia. Annals of the New York Academy of Sciences, 80, 384-394.

Siggard-Andersen, O. (1963). Blood acid-base alignment nomogram. Scandinavian Journal of Clinical and Laboratory Investigation. 15, 211-217.

Turnbull, A. D., and Dobell, A. R. C. (1966). The effect of pH change on the ventricular fibrillation threshold. Surgery, 60, 1040-1043.

Weidmann, S. (1956). Elektrophysiologie der Herzmuskelfaser, p. 81. Huber, Berne, Switzerland.

West, T. C., and Landa, J. F. (1962). Minimal mass required for induction of a sustained arrhythmia in isolated atrial segments. Americal Journal of Physiology, 202, 232-236.

Young, W. G., Sealy, W. C., and Harris, J. S. (1954). The role of intracellular and extracellular electrolytes in the cardiac arrhythmias produced by prolonged hypercapnia. Surgery, 36, 636-649.

Received for publication August 18, 1972.

Accepted for publication November 14, 1972. 
service, and also the various types of special examinations. The chapter on 'Well person screening' is written by that redoubtable protagonist, Dr. H. Beric Wright. Treatment services, epidemiological methods, and field surveys have a chapter each, as does also the important subject of absence from work supported by a medical certificate.

In the second half of the book the emphasis becomes more environmental, with chapters upon the psychosocial and organizational environment, ergonomics, the physical and thermal environment, airborne contaminants, ventilation, protective clothing, and mental health. There are further chapters on occupational safety and accident prevention and the prevention of occupational disease and ethics in occupational health practice, and the book closes with a chapter on education in occupational health. There is a clear index and a list of contributors stating who they are, which adds to the interest. The book is interspersed with clearly designed tables and line diagrams. It is bound in a tasteful maroon colour with gold lettering.

If I were asked 'What is occupational health?' by a sceptical colleague, I feel that I could not do better than press this book into his hand, and at $£ 4.50$ it would be quite good value.

R. C. Browne

\section{NOTICES}

\section{Second International Advanced Course in Epidemiological Methods}

The Institute of Occupational Health, Helsinki and the Industrial Medical Association of Finland are arranging a course in epidemiological methods, with special reference to occupational health problems, in Helsinki, Finland, 20-31 August 1973. The Director and main lecturer will be Professor Olli S. Miettinen, M.D., Ph.D. The course will be in English and a maximum of 30 participants will be accepted. An academic degree in medicine, chemistry, technology, sociology, or related fields is required. The fee is $\$ 120$.

Further details are available from Sven Hernberg, M.D., Director of Epidemiology and Biometry, Institute of Occupational Health, Haartmaninkatu 1, 00290 Helsinki 29, Finland.

\section{Laser Safety Course}

The Medical Laser Laboratory and the Office of Continuing Medical Education (CONMED) of the University of Cincinnati, Ohio announce the fifth semi-annual Short Course on Laser Safety 6-10 August 1973 at the University of Cincinnati, Ohio.

For further information contact Laser Safety Course, CONMED, 114 Medical College, Cincinnati, Ohio 45219, U.S.A.

\section{British Occupational Hygiene Society}

It is proposed to hold a fourth International Symposium on Inhaled Particles and Vapours in September 1975 in the United Kingdom, provisionally at Edinburgh. (The dates of the Symposium will be close to, but will not overlap those of the International Conference on Occupational Health which, it is anticipated, will be held in the same month.)

The Symposium will again aim to present the results of the latest research ino the inhalation and retention of harmful dusts, gases and vapours, the way they are handled by the body and their effects; it will be concerned with basic mechanisms rather than with case histories.

Further information may be obtained from Mr. W. Wood, Institute of Occupational Medicine, Roxburgh Place, Edinburgh, EH8 9SU.

\section{Fifth Summer School on Alcoholism}

The fifth annual Summer School on Alcoholism will be held at the Brighton College of Education, Falmer, 1-7 September 1973, under the auspices of the Alcoholism Education Centre which receives support from the Department of Health and Social Security.

The aim of the School is to broaden their basis of knowledge about alcoholism in its more important aspects, so that those working in this field will become better equipped for their task.

Applications are invited from social workers (including supervisory staffs of hostels), students of social science, nurses, doctors, probation, prison, and Local Authority social workers, health education officers, health visitors, magistrates, teachers, and all professional groups involved in the problems raised by alcoholism.

Further information may be obtained from The Summer School on Alcoholism, The Maudsley Hospital, Denmark Hill, London SE5 8AZ.

\section{Medical Code of Practice for Work in Compressed Air CIRIA Report 44}

This new Medical Code, intended for work in compressed air in tunnels, in caissons or other pressure chambers, results from investigations carried out over a number of years, in co-operation with CIRIA, by members of the Medical Research Council's Decompression Sickness Central Registry.

The new Code includes recommendations on general medical supervision, compression and decompression procedures and, unlike the previous regulations, recommends treatment procedures for decompression sickness. It also incorporates for the first time the now well established 'Blackpool' Decompression Tables.

Further details from D. E. Lennard, CIRIA, Telephone 01-839 6881 .

\section{CORRECTION}

'Ventricular fibrillation threshold for AC shocks of long duration, in dogs with normal acid-base state' by Janet R. Scott, W. R. Lee, and S. Zoledziowski, vol. 30, 155161.

Throughout the abstract of this paper the currents are wrongly stated as micro amps $(\mu \mathrm{A})$ whereas they should be in milli amps (mA). 